https://doi.org/10.52449/1857-4114.2021.37-1.07

CZU: 612:796.322-053.9

\title{
ASSESSMENT OF PHYSICAL CONDITION OF SENIOR HANDBALL PLAYERS
}

\author{
Timofte Mihai ${ }^{1}$, ORCID: 0000-0001-5636-7862 \\ ${ }^{1}$ Titu Maiorescu Secondary School, Iasi, Romania
}

\begin{abstract}
The objective of the research was to obtain useful information on physical training for senior handball players, for this purpose we developed and applied a training plan designed to achieve a high level of physical training. Each test applied to athletes was relevant, in order to obtain useful information on physical training, for senior handball players. Specialization and differentiated treatment of players during training is a fundamental methodological orientation in modern sports training, required by the heterogeneous composition of groups of players in terms of somato-functional development and motor skills qualities.

The research conclusions, obtained after applying the initial and final tests, indicate the need to apply training programs specific to the sport played, customized according to the specifics of the game, age and motor experience, to improve the physical training of senior handball players. A good physical condition and specific to the handball game is essential in the current handball game and offers the optimal conditions for obtaining sports performance. A contribution to the development of the training process has the training plan which establishes the objective, the share of specific training factors for each training stage.

The means and methods exposed in the training program of the experiment group were successful, and its effect materialized through a real increase in motor skill indices. At the final test, the athletes included in the control group reported a relative and insignificant evolution of the specific physical condition, at the final tests for the evaluation of the specific physical condition obtaining a significant improvement of the results.
\end{abstract}

Keywords: physical training, physical condition, final test, physical tests, handball players.

\section{Introduction}

Sports training (including the course physical training) is widely presented in the literature. Regarding the physical training, it is specified its presence in all stages of training, in different weights, it contributing to the realization of sports training and obtaining performances in competitions [2, 3, 4, 6, 7].

Physical training is an indispensable element for sports performance and intervenes decisively in an optimal development of all indicators that manifest the main physical qualities - strength, speed, endurance, suppleness and dexterity, all in close relation to the characteristics of sports.
A good physical training of high performance handball players, along with native features, ensures an optimal level of development in terms of performance, manifested by speed, strength, relaxation and very good aerobic performance, along with somatic cues required by handball during current - taller, stronger players with higher body weight [8].

The training of high-performance handball players must be correlated with the situations encountered in the game and which they must face successfully. The most common motor skill demands in competitions are: high intensity actions, physical contact and resilience during the game [1]. 
Top handball players are distinguished by individual physical performance in terms of relaxation, strength, specific strength, speed on short distances.

Physical training, programmed in accordance with the individual characteristics of athletes contributes to the development of motor skill and physical potential, which is crucial in achieving performance, a significant contribution having the strength and power developed in the context of training specific to handball [5].

Training for the physical training of elite handball players must include means that contribute to the development of strength and power, specific coordination and endurance, agility and relaxation, through training with high intensity intervals and short duration (up to 15 seconds), the effect final being visible in achieving an optimal level of training, which will contribute to the achievement of the set performance objectives [9].

Physical training in handball is a complex task, because it must be planned and correlated with the other aspects of sports training (technical, tactical, psychological), the specifics of the playing positions and the individual characteristics of the players, to ensure the optimal development of fitness.

\section{Materials and methods}

In conducting the research we started from the hypothesis that the implementation of a training program containing means adapted to the game model in performance handball at senior level will lead to the improvement of the specific physical condition of senior handball players.

Each of the two groups consisted of 19 athletes, to whom the following tests were applied: speed / sprint $(10 \mathrm{~m}, 20 \mathrm{~m})$, Illinois test (agility), 30/15 IFT test (endurance).

The initial testing period was July 12-14, 2019, Calarasi, for the experimental group, respectively August 1-3, 2019, Iasi, for the control group, at the beginning of the centralized training of the team.

The final testing period took place between December 14-16, 2019, Calsrasi, for the experimental group, respectively December 1113, 2019, Iasi, for the control group, before the competition break.

\section{Results and discussion}

Within the groups, on play stations, there are small differences, the values obtained at the control tests, at the initial testing, by the athletes from the experiment group are slightly higher than those obtained by those of the control group (Tables 1 and 2; Figures 1 and 2).

Table 1. Tests and results on initial testing. Intergroup statistical analysis. Running tests

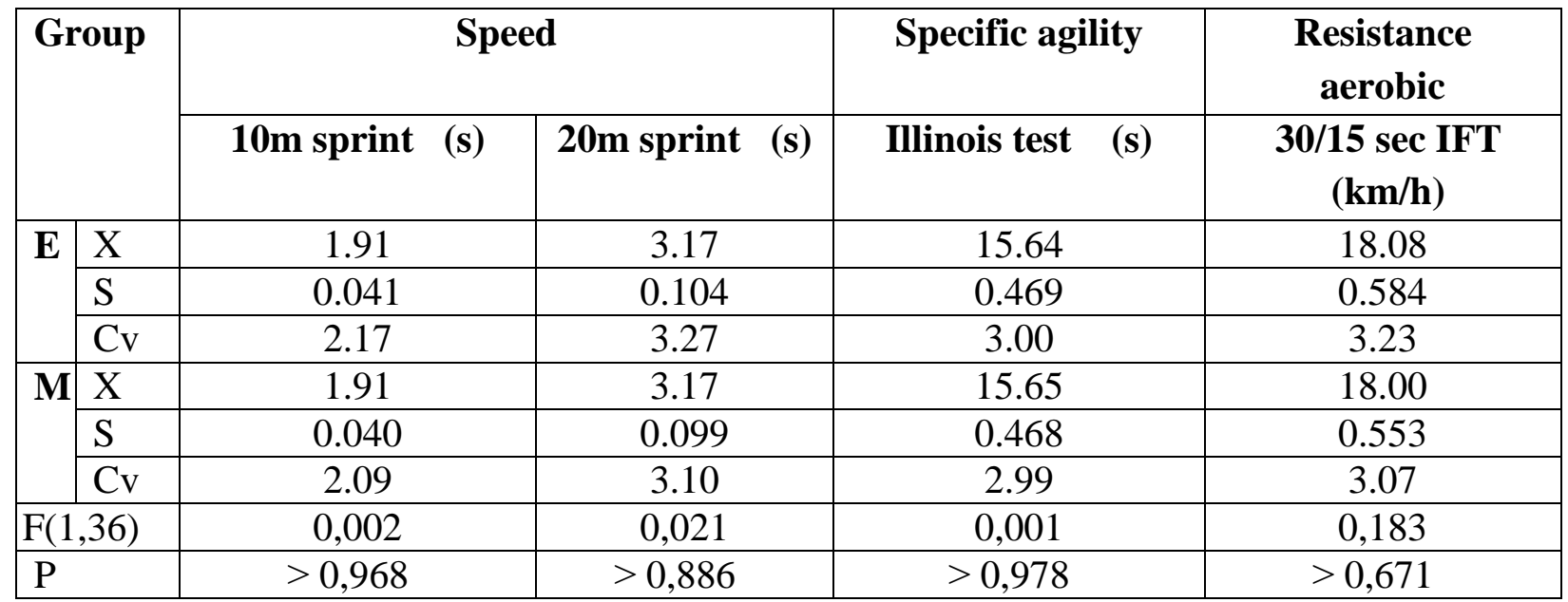


Table 2. Final results and tests. Intergroup statistical analysis

\begin{tabular}{|c|c|c|c|c|c|c|c|c|c|}
\hline \multicolumn{2}{|c|}{ Group } & \multicolumn{2}{|c|}{ Speed } & \multirow{2}{*}{$\begin{array}{c}\text { Specific } \\
\text { agility } \\
\text { Illinois } \\
\text { test } \\
\text { (s) } \\
\end{array}$} & \multirow{2}{*}{$\begin{array}{c}\begin{array}{c}\text { Resista } \\
\text { nce } \\
\text { aerobic }\end{array} \\
30 / 15 \\
\text { sec IFT } \\
(\mathbf{k m} / \mathbf{h})\end{array}$} & \multicolumn{3}{|c|}{ Strenght } & \multirow{2}{*}{$\begin{array}{c}\begin{array}{c}\text { Isometric } \\
\text { force }\end{array} \\
\begin{array}{c}\text { Plank } \\
\text { (s) }\end{array}\end{array}$} \\
\hline & & $\begin{array}{l}10 \mathrm{~m} \\
\text { sprint } \\
(\mathrm{s})\end{array}$ & $\begin{array}{c}20 \mathrm{~m} \\
\text { sprint } \\
(\mathrm{s})\end{array}$ & & & Semi-squat & Bench press & $\begin{array}{c}\text { Upright } \\
\text { Barbell Row }\end{array}$ & \\
\hline \multirow[t]{3}{*}{$\mathbf{E}$} & $\mathrm{X}$ & 1.86 & 3.09 & 15.50 & 19.29 & 141.47 & 83.79 & 42.32 & 152.11 \\
\hline & S & 0.038 & 0.100 & 0.438 & 0.839 & 12.817 & 6.989 & 4.978 & 26.104 \\
\hline & $\mathrm{Cv}$ & 2.07 & 3.24 & 2.83 & 4.35 & 9.06 & 8.34 & 11.76 & 17.16 \\
\hline \multirow[t]{3}{*}{$\mathbf{M}$} & $X$ & 1.91 & 3.17 & 15.64 & 18.16 & 126.42 & 75.79 & 34.16 & 127.63 \\
\hline & $\mathrm{S}$ & 0.040 & 0.097 & 0.467 & 0.443 & 10.976 & 8.324 & 4.272 & 27.048 \\
\hline & $\mathrm{Cv}$ & 2.10 & 3.06 & 2.99 & 2.44 & 8.68 & 10.98 & 12.51 & 21.19 \\
\hline \multicolumn{2}{|c|}{$\mathrm{F}(1,36)$} & 14,136 & 6,007 & 0,956 & 27,058 & 15,119 & 10,294 & 29,382 & 8,054 \\
\hline \multicolumn{2}{|c|}{$\mathrm{P}$} & $<0,001$ & $<0,019$ & $>0,335$ & $<0,001$ & $<0,001$ & $<0,003$ & $<0,001$ & $<0,007$ \\
\hline
\end{tabular}

At the $\mathbf{1 0} \mathbf{~ m}$ sprint test, the experiment group obtained a progress of $0,05 \mathrm{sec}$ (having an average of $1,91 \mathrm{sec}$ at the initial test and $1,86 \mathrm{sec}$ at the final test); In percentage terms, the progress was $2,62 \%$. By applying the simple intragroup ANOVA technique to the experiment group, an $\mathrm{F}$ value of 14,540 was obtained, a significant value for the limit of $10,1 \%(\mathrm{P}<0,001)$. The control group did not register any increase between the two tests (initial test 1,91 sec, and final test also 1,91 sec). The same technique applied to the control group indicated an $\mathrm{F}$ value of 0.030 at a $\mathrm{P}$ limit of 0,871 , thus above the $\mathrm{P}$ value of 0,05 , the minimum limit accepted in such research. At the initial testing between the two groups there were no differences (control group - 1,91 sec; experiment group - 1,91 sec), a fact confirmed by the application of the simple intergroup ANOVA technique that did not indicate statistical significance. The analysis of the intergroup statistical significance at the final testing indicated a value of 14,136 for F, a statistically significant value for the $\mathrm{P}$ limit of 0,001 .

Regarding the $\mathbf{2 0}$ meter sprint test, the experiment group obtained a progress of 0,08 sec (having at the initial test an average of 3,17 $\mathrm{sec}$, and at the final one of $3,09 \mathrm{sec}$ ); In percentage terms, the progress was $2,52 \%$. By applying the simple intragroup ANOVA technique to the experiment group, an $\mathrm{F}$ value of 5,460 was obtained, the significant value for the P limit of 0,025 . The control group did not register any increase between the two tests (initial test 3,17 sec, and final test also 3,17 $\mathrm{sec})$. The same technique applied to the control group indicated a value for $\mathrm{F}$ of 0,013 at a limit for $\mathrm{P}$ of 0,908 , thus above the value of 0,05 , the minimum limit accepted in such research. At the initial testing between the two groups there were no differences (control group - 3,17 sec; experiment group - 3,17 sec), a fact confirmed by the application of the simple intergroup ANOVA technique that did not indicate statistical significance. The analysis of the intergroup statistical significance at the final test indicated a value of 6,007 for $F$, a statistically significant value for the P threshold of 0,019 .

Regarding the Illinois test, the experiment group obtained a progress of $0,14 \mathrm{sec}$ (having at the initial test an average of 15,64 sec, and at the final test of $15,50 \mathrm{sec}$ ); In percentage terms, the progress was $0.9 \%$. By applying the simple intragroup ANOVA technique to the experiment group, an $\mathrm{F}$ value of 1,002 was obtained, the insignificant value for the limit 
of 0,323 . The control group registered in the two tests an increase of 0.01 (initial test 15.65 $\mathrm{sec}$, and final test $15.64 \mathrm{sec})$, in percentage $0,06 \%$. The same technique applied to the control group indicated a value for $\mathrm{F}$ of 0.003 at a limit for $\mathrm{P}$ of 0.959 , the value of $\mathrm{P}$ should be 0.05 or less to be significant. At the initial testing between the two groups there were no significant differences (control group - 15.65 sec.; experiment group - $15.64 \mathrm{sec}$.), a fact confirmed by the application of the simple intergroup ANOVA technique that did not indicate statistical significance. The analysis of the intergroup statistical significance at the final test indicated a value of 0.956 for $F$, a statistically insignificant value for the $\mathrm{P}$ limit of 0.335 .

At the 30/15 IFT test, the experiment group obtained a progress of $1,21 \mathrm{~km} / \mathrm{h}$ (having at the initial test an average of 18.08 $\mathrm{km} / \mathrm{h}$, and at the final one of $19,29 \mathrm{~km} / \mathrm{h}$ ); In percentage terms, the progress was $6,69 \%$. By applying the simple intragroup ANOVA technique, in the experiment group an $\mathrm{F}$ value of 26,662 was obtained, the significant value for the limit of $0,1 \%$. The control group registered in the two tests an increase of 0,16 $\mathrm{km} / \mathrm{h}$ (initial test $18 \mathrm{~km} / \mathrm{h}$, and the final test $18,16 \mathrm{~km} / \mathrm{h}$ ), in percentage 0,89 . The same technique applied to the control group indicated a value for $\mathrm{F}$ of 0,945 at a limit for $\mathrm{P}$ of 0,388 , thus above the value of 0,05 , the minimum limit accepted in such research. At the initial testing between the two groups there were no significant differences (control group - $18 \mathrm{~km} / \mathrm{h}$; experiment group - 18,08 km/h), a fact confirmed by the application of the simple intergroup ANOVA technique that did not indicate statistical significance. The analysis of the intergroup statistical significance at the final testing indicated a value of 27,058 for $\mathrm{F}$, a statistically significant value for the $\mathrm{P}$ limit of 0,001 .

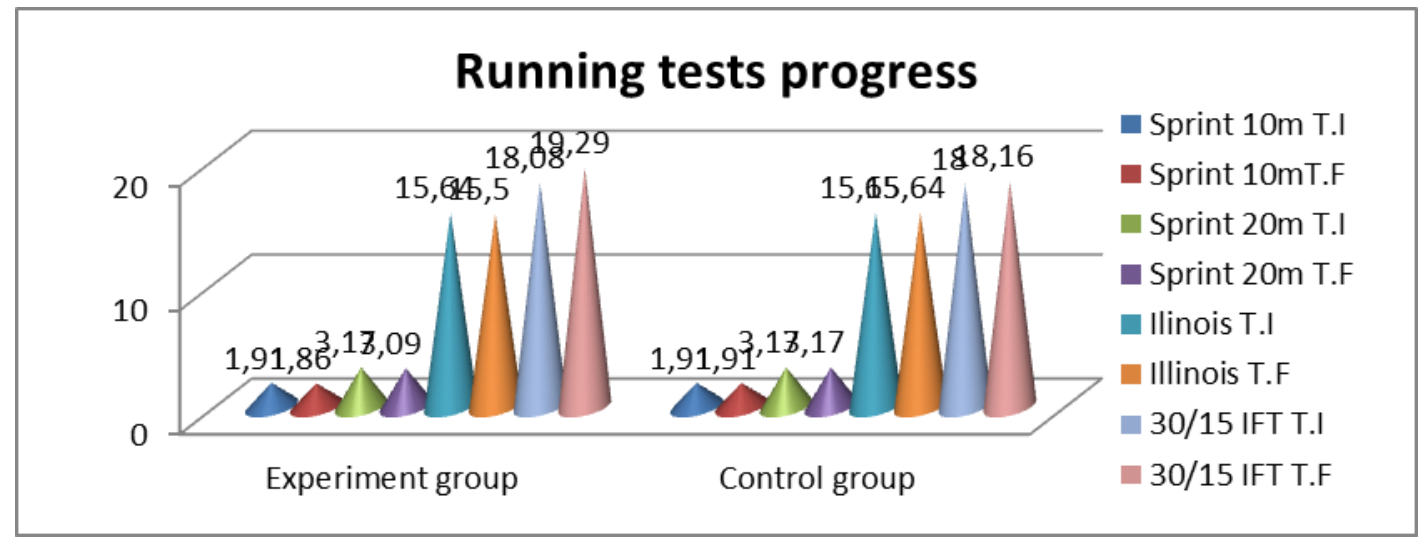

Fig. 1. Graphical representation of the results recorded by the two groups at the running tests (initial and final tests)

Overall, the average rate of progress recorded by the experiment group was $0,09 \mathrm{sec}$, in $3,18 \%$ percent, and in the control group the progress obtained was only $0,003 \mathrm{sec}$, in $0,24 \%$ percent, after the period subjected to the experiment. The most important advances were those registered by the experiment group in the running tests, 30/15 IFT $(\mathbf{1 . 2 1} \mathbf{~ k m ~ / ~ h ) , ~}$ in percentage $6.69 \%$, and sprint $\mathbf{1 0}$ meters $(0.05 \mathrm{sec})$, in percentage $2,62 \%$, following the
20 meter sprint trials (0.08 $\mathbf{~ s e c})$, in $2,52 \%$ percent and in the Illinois test $(0.14 \mathrm{sec})$, respectively, in $0.9 \%$ percent. In the control group, the only significant progress was in the 30/15 IFT test $(0.16 \mathrm{~km} / \mathrm{h})$, in percentage $0,89 \%$.

Even in the running trials, compared to the control group, the progress of the experiment group was higher, after the period subjected to the experiment. 


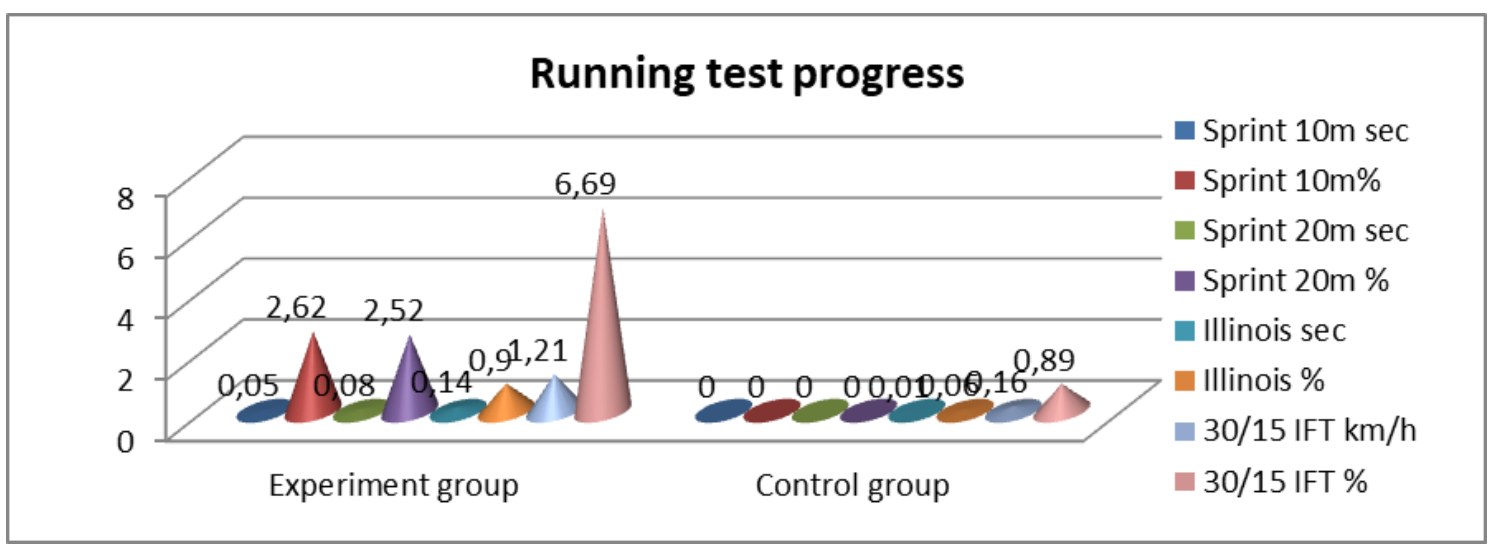

Fig. 2. The graph representing the overall progress made by the players of the two groups in the running tests at the final test

\section{Conclusions}

As a result of the application of the methods exposed in the training program of the experiment group, a real increase of the motor skill indices was highlighted. At the final test, at the tests for the evaluation of the specific physical condition, a significant improvement of the results was obtained (progresses made: running speed / sprint 10m $0.05 \mathrm{sec}$; running speed / sprint $20 \mathrm{~m}-0.08 \mathrm{sec}$; Illinois test - $0.14 \mathrm{sec} ; \quad 30 / 15$ IFT respectively $1.21 \mathrm{~km} \mathrm{/} \mathrm{h).} \mathrm{Comparing} \mathrm{the}$ results obtained by the experimental group at the final testing of the control group, it can be concluded that the exposed means had an increased influence in the development of the specific physical condition of the subjects in the experimental group.

Both the training plans and the planning of the physical training sessions performed by us determined an improvement of the specific physical condition of the handball players subjected to testing in the experimental group. The athletes included in the control group reported a relative and insignificant evolution of the specific physical condition.

An optimal level of physical condition specific to the handball game is essential in the current handball game and offers the premises for obtaining sports performance.

\section{References:}

1. Barbero J.C., Granda-Vera J., Calleja-Gonzalez J., Del Coso J. (2014). Physical and physiological demands of elite team handball players. International Journal of Performance Analysis in Sport, Vol. 14, No. 3, p. 921-933.

2. Bompa T. (2001). Periodizarea: Teoria și metodologia antrenamentului. București: Editura Ex Ponto, p. 5.

3. Bota I. (1984). Modele de joc și pregătire. București: Editura Sport-Turism, p. 21, 203.

4. Colibaba-Evuleț D., Bota I. (1998). Jocuri sportive, teorie și metodică. București: Editura Aldin, p. 187-195, 201-224.

5. Gorski M., Starczewski M., Pastuszak A., Mazur-Rozycka J., Gajewski J., Busko K. (2018). Changes of strength and maximum power of lower extremities in adolescent handball players during a two-year training cycle. Journal of Human Kinetics, Vol. 63, No.1, p. 95-103.

6. Kunst - Ghermănescu I., Gogâltan V., Jianu E., Negulescu I. (1983). Teoria şi metodica handbalului. București: Editura Didactica si Pedagogica, p. 54-62, 79, 105.

7. Mihăilă I. (2006). Evaluarea în selecția și pregătirea handbaliștilor de performanță. Craiova: Editura Universitaria, p. 25, 41-56.

8. Wagner H., Fuchs P. X., Von Duvillard S. P. (2018). Specific physiological and biomechanical performance in elite, sub-elite and in non-elite male team handball players. Journal of Sports Medicine and Physical Fitness, Vol. 58, No. 1-2, p. 73-81.

9. Wagner H., Gierlinger M., Adzamija N., Ajayi S., Bacharach D.W., Von Duvillard S.P. (2017). Specific physical training in elite male team handball. Journal of Strength and Conditioning Research, Vol. 31, No. 11, p. 3083. 